\title{
DRYING OF REFUSE-DERIVED FUEL (RDF) USING SOLAR TUNNEL DRYER INTEGRATED WITH FLAT-PLATE SOLAR COLLECTOR: AN EXPERIMENTAL APPROACH
}

\author{
Tamer M. Ismail ${ }^{1}$, Khaled Ramzy ${ }^{1, *}$ and Hisham Sherif ${ }^{2}$ \\ ${ }^{1}$ Department of Mechanical Engineering, Suez Canal University, Ismailia, Egypt \\ ${ }^{2}$ Department of Mechanical Engineering, Minya University, Minya, Egypt
}

Article Info:
Received:
7 January 2020
Revised:
26 June 2020
Accepted:
1 July 2020
Available online:
30 November 2020
Keywords:
Drying
RDF
Solar energy
Moisture content
Drying efficiency

Article Info:

7 January 2020

Revised:

Available online:

November 2020

Keywords:

Moisture conten

Drying efficiency

\begin{abstract}
Solar energy can be effectively used for drying, especially when the cost of fuel used for conventional dryers is high. The drying of refuse-derived fuel (RDF) is a complicated process involving mass and heat transfer and depends on external variables such as humidity, temperature, and air velocity as well as internal variables, e.g., material surface, physical structure, chemical composition, size, and shape. Herein, a solar tunnel dryer integrated with a flat-plate solar collector was designed and fabricated at the Faculty of Engineering, Suez Canal University, Egypt. The experiments were performed during July 2019. The weather characteristics as well as the variation in moisture content with time were recorded continually. The results indicated that the maximum efficiencies of the solar collector were $46.6 \%, 53.4 \%$, and $40.0 \%$ on 2,4 , and 6 July, 2019, respectively. Moreover, on these days, the moisture content of RDF decreased from $35.6 \%$ to $9.6 \%$, from $28.3 \%$ to $8.5 \%$, and from $43.5 \%$ to $14.0 \%$. The dryer efficiency varied over $14.1-29.5 \%$ depending on the drying air stream temperature. The maximum dryer efficiencies recorded were $23.8 \%, 29.5 \%$, and $25.8 \%$ on 2 , 4, and 6 July, 2019, respectively.
\end{abstract}

\section{INTRODUCTION}

Drying is one of the most important applications of solar energy. One of the oldest practices is the drying of food in the sun. Heat is generated in the interior and surface of the product, which enhances heat transfer. The absorption of solar radiation by the product is the main principle of direct solar drying, Ekechukwu, O. and Norton, B., (1999). In indirect solar drying, the products are spread in thin layers and exposed directly to the sun's radiation. This method is the least expensive and is employed worldwide, but there is significant risk of deterioration owing to infestation and dust accumulation, Fadhel, A., et al. (2005). To avoid these problems, solar dryers should be used on a large scale for drying products, especially in the food industry. There are three main categories of solar dryers: direct, indirect, and infrared radiant heat dryers. Solar dryers have been used in several different environmental engineering applications such as refuse-derived fuel (RDF) drying, municipal solid waste (MSW) drying, and sludge dewatering, He, P., (2009).

Presently, the most common and widely used MSW drying methods include bio-stabilisation, bio-drying, thermal drying, and solar drying, Ferreira, A., et al. (2014). Refuse-derived fuel refers to the materials derived from MSW through many processes such as sorting, screening, separation at source, blending, and pelletising, Asadi, F., (2016). Compared with coal, RDF, as a fuel, has lower calorific value and S content and higher amounts of $\mathrm{Cl}$. Many factors should be considered in the use of RDF, such as moisture content, alkaline and $\mathrm{S}$ compounds, calorific value, and ash content, Beyene, H., et al. (2018). Furthermore, RDF can be utilised to generate thermal energy in combustion, gasification, and pyrolysis. The most important problem faced by industries currently is the high water content of all solid fuels, which must be decreased to improve their fuel heating values, as reported in the literature, [Luca, A. and Raffaello, C., (2015), Golisz, E., (2013) and Yuan, J. et al. (2017)].

Organic waste from food factories, lunchrooms, and kitchens has high moisture content and high biodegradability. To reuse such waste in industries, its moisture content should be reduced and controlled as soon as possible to obtain low ash content. At low water content, the risk of spontaneous combustion increases and the energy efficiency of shredding such waste enhances. However, at excessive water content, the relaxation coefficient is high, Koser, H., et al. (1982).

Hence, the control process and presence of moisture content significantly impact the calorific values of fuels, 
e.g., humidity must not exceed $15 \%$ in a cement kiln, Yasuhara, A., et al. (2010). However, the low moisture content of RDF renders it difficult to handle during transportation owing to dust and blockages on conveyor belts. Given the low intrinsic market value of RDF, its collection and transport logistics are considerably important to facilitate adequate quantities that allow economical disposal of waste [Caputo, A., and Pelagagge, P., (2002), Caputo, A., et al. (2004) and Peng Lu. et al. (2017)]. Many scientists and organisations have carried out several studies on RDF drying methods. Some of these studies focus on product types and pre-treatment methods, as discussed by Mumba, J. (1996) and Prasad, J., et al. (2006). Jannot, Y. and Coulibaly, Y., (1998) studied the effects of climate factors such as humidity and drying air temperature on the drying process and solar dryer performance.

The greatest disadvantage of the drying process is its high energy consumption; therefore, solar dryers are considered the most economical alternative. Several studies have been carried out on different drying techniques using solar energy. Kabeel, A., (1998) studied the shape optimisation of the absorber plates of solar air collectors and determined that the shape absorber factor played a vital role in the design of solar air heaters and that the optimum tilt angle of the triangular collectors was in the range 50$60^{\circ}$. Kabeel, A., et al. (2017) presented a detailed review of the design, applications, configurations, and improved methods of solar air heaters. They concluded that artificial roughness can be used to enhance the heat transfer rate and thermo-hydraulic performance of solar air heaters.

Additionally, the use of phase-change materials as heat storage materials was found to improve the efficiency of solar air heaters. Abdullah, A., et al. (2018) presented an experimental study to evaluate the performance of a new double-pass solar air heater, with and without turbulators, at different values of air mass flow rate in the range $0.02-$ $0.05 \mathrm{~kg} / \mathrm{s}$. They achieved a maximum daily efficiency of $68 \%$ using a staggered double-pass solar air heater at an air mass flow rate of $0.05 \mathrm{~kg} / \mathrm{s}$.

Kabeel, A., et al. (2018) studied the performance of a baffled glazed-bladed entrance solar air heater and compared the results with those of a conventional equipment under the same operating conditions. Their results showed that the daily efficiency of the solar air heater considered with 800 baffles was $29.91-51.69 \%$ higher than that of the conventional one. Zamrudy, W., et al. (2019) reviewed different RDF drying technologies for subsequent use of RDF in the cement industry. It can be concluded from their review that the main drying equipment for RDF include a conveyor belt dryer, Torbed reactor, screw conveyor, indirect rotary dryer, and direct rotary drum dryer.

Herein, a solar tunnel dryer integrated with a flat-plate solar air collector was designed, fabricated, and tested for drying RDF. The experimental data were used to investigate the performance of the solar dryer and evaluate the flatplate solar collector efficiency and drying efficiency. The results obtained were validated and compared with previously reported findings for solar air collectors. Furthermore, the results were evaluated and compared with those obtained for the direct exposure of RDF to the sun under the same climatic and operating conditions.

\section{MATERIALS AND METHODS}

\subsection{Experimental Set-up and Procedure}

The experimental set-up was designed, installed, and tested at the Faculty of Engineering, Suez Canal University, Ismailia $\left(30^{\circ} 36^{\prime} \mathrm{N}, 32^{\circ} 16^{\prime} \mathrm{E}\right)$, Egypt. The set-up consisted of a solar tunnel dryer integrated with a piping system, a flatplate solar air collector (dimensions of $1.5 \times 1 \times 0.15 \mathrm{~m}$ ), solar panels (eight panels of $250 \mathrm{~W}$ each), an inverter with a controller, a centrifugal blower, and a fan. The solar tunnel dryer was constructed from materials readily available in the local area and had a metallic frame structure with dimensions of $2 \times 1.5 \times 1 \mathrm{~m}$. The piping system consisted of two main pipes with a diameter of 2 inches. Small-holed pipes, 0.75 inches in diameter, were welded to the two main pipes to diffuse hot air into the solar tunnel dryer.

The performance of the dryer was evaluated in July 2019. The layout with a schematic diagram of the experimental set-up is shown in Figure 1. A transparent plastic cover was used to cover the tunnel dryer to transmit sunlight into and prevent air leakage from the dryer. An insulating material was used to reduce conductive losses from the bottom. A small fan was installed on the ceiling of the solar tunnel dryer to circulate air when the specific humidity increased. Such an equipment can dry different types of materials and the drying air temperature should be maintained $10-30^{\circ} \mathrm{C}$ higher than the ambient temperature, as suggested in the literature (Elicin, A., and Sacilik K., (2005), Kooli, S., et al. (2007), Hossain, M., and Bala, B.,(2007) and Usub, T., et al. (2008)).

The air inside the solar tunnel dryer must be maintained at a high temperature to increase the driving force for evaporation. Moreover, the relative humidity must be maintained far from the saturation point to increase the water-vapor-carrying capacity of air and to avoid condensation inside the tunnel dryer. Therefore, ventilation with a certain degree of control was required in the solar tunnel dryer. A personal computer processor fan was placed on the ceiling to change the air feeding rate inside the greenhouse at high values of internal humidity. This fan had eight blades and a diameter of $0.15 \mathrm{~m}$. It was operated for $3 \mathrm{~min}$ every $2 \mathrm{~h}$. The solar tunnel dryer was connected to a data acquisition system to automatically record the temperatures using resistance temperature detectors (RTDs). The ambient temperature and the temperatures at the collector outlet and inside the solar tunnel dryer were measured.

The solar radiation intensity and wind velocity were additionally measured on the days of the experiment. Figure 2 shows a photograph of the complete set-up used to obtain the experimental results. The RDF, with a particle size of $60-80 \mathrm{~mm}$, was spread on the drying floor and placed inside the solar tunnel dryer. More than 20 test runs were conducted. The selected days were 2, 4, 6, and 8 July 2019, based on their similar weather characteristics. Each test run was started at 9:00 AM and continued until 5:00 PM and the measured parameters were recorded instantaneously every $30 \mathrm{~min}$. The samples were distributed in layers to receive the same amount of solar radiation. The results of 


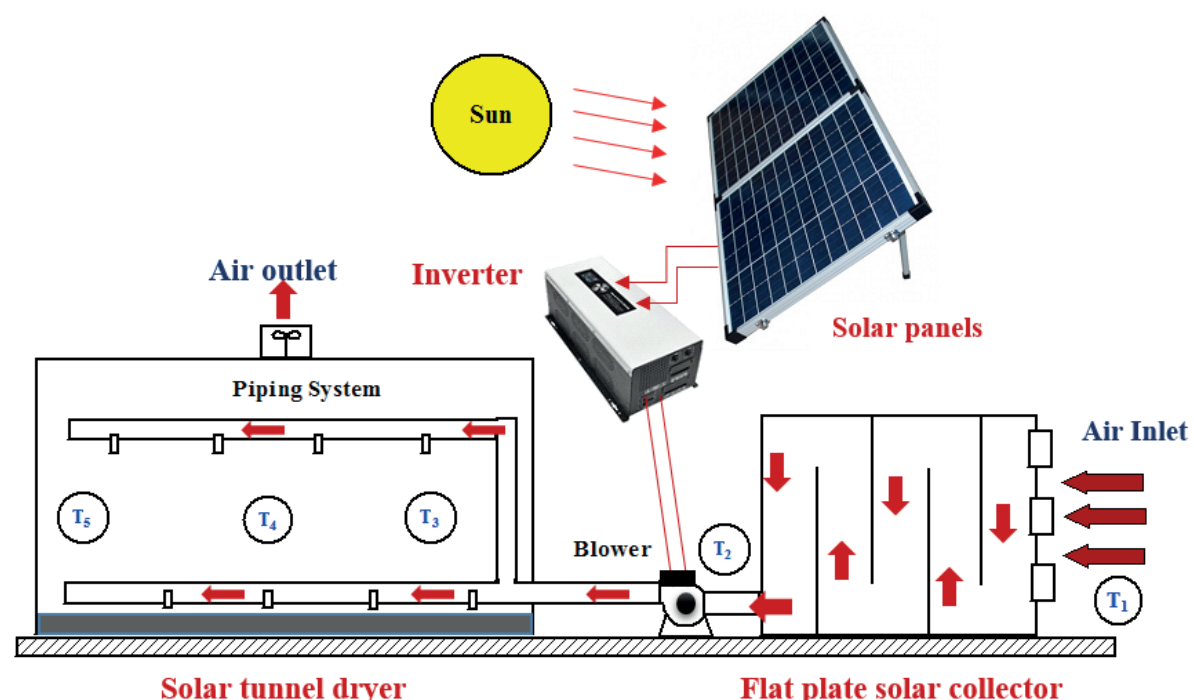

FIGURE 1: Schematic diagram of experimental set-up.

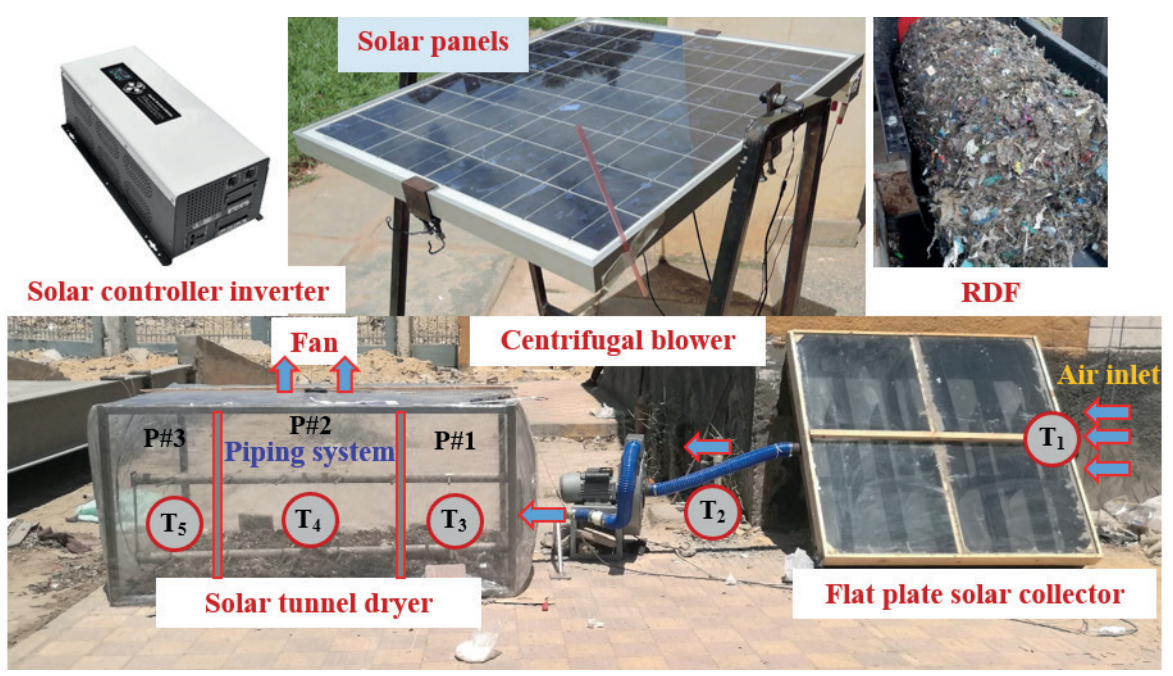

FIGURE 2: Photograph of experimental set-up.

natural drying, wherein RDF was placed in the sun for direct exposure, were additionally obtained and compared. At the beginning of the experiment, the RDF was mixed to ensure homogeneity.

All the experiments were repeated with the same quantity of RDF, which was pre-dried in the instrument and re-wetted to ensure that the apparatus had the ability to dry RDF under various conditions. The initial weight of the sample and ambient conditions were measured. The different climate parameters and RDF moisture content were recorded every hour. The measurements were repeated until the RDF inside the solar tunnel dryer exhibited no change in moisture content.

\subsection{Measurements and Instruments}

This section presents the instruments used to measure different parameters such as solar radiation intensity, temperature inside the solar tunnel dryer, wind velocity, moisture content, and ambient temperature. Solar radiation in- tensity is the basic parameter for the drying process. Solar panels (also known as photovoltaic panels) were used to convert sunlight to electricity, which was used to power the centrifugal blower and the fan in the ceiling of the solar tunnel dryer. The inverter was used to convert direct current to alternating current to operate the centrifugal blower. The flat-plate solar collector was used to absorb the incoming solar radiation, convert it to heat, and transfer this heat to the ambient air at the inlet of the collector.

The centrifugal blower was used to draw the ambient air into the flat-plate solar collector. The air started to heat and reached the solar tunnel dryer at a high temperature. In this work, an Eppley PSP pyranometer was used to measure the global solar radiation on the days when the experiment was conducted. This instrument measures the global solar radiation (in $\mathrm{W} / \mathrm{m}^{2}$ ) incident from all directions. The apparatus was mounted on a table and adjusted horizontally using adjustable levelling screws and a built-in water balance and was connected to a digital output screen to re- 
cord the values, as shown in Figure 3-a. An advanced platinum RTD temperature sensor was used in the experimental set-up to measure the temperatures at different positions.

Two sensors were used to measure the air temperature at the inlet $\left(T_{1}\right)$ and outlet $\left(T_{2}\right)$ of the solar collector. The RTD temperature sensors were fixed inside the solar dryer at three different positions, i.e., $P \# 1\left(T_{3}\right), P \# 2\left(T_{4}\right)$, and P\#3 $\left(T_{5}\right)$, as shown in Figure 2. These sensors have a data logger for collecting the data measured on the days when the experiment was conducted. The temperature sensors had a measurement range from $-50^{\circ} \mathrm{C}$ to $+350^{\circ} \mathrm{C}$ with a resolution of $0.1^{\circ} \mathrm{C}$.

Wind velocity is another parameter affecting the solar dryer performance. On each day of the experiment, the wind velocity was measured every $30 \mathrm{~min}$. A digital advanced anemometer, type Xplorer4, was used to measure the wind velocity. The measurement range of the apparatus was $0-42 \mathrm{~m} / \mathrm{s}$. The average values of wind velocity were calculated for each day.

The moisture content was determined using the drying oven and balance apparatus shown in Figure 3-c. The RDF samples were heated and their weight loss owing to moisture evaporation was recorded simultaneously every hour.

\subsection{Error Analysis}

There are many different types of errors and uncertainties in experiments. These can originate from the selection, calibration, and condition of the instruments used, observation environment, test planning, and reading of measurements. In the RDF drying experiments, the weights and temperatures were measured with the appropriate instruments. The Holman, J., (1994), method was used to estimate the uncertainty in the experimental results. The uncertainty was calculated based on the minimum error, i.e., the ratio of the least count of the apparatus to the minimum output of measured value, Kabeel, A., (2009). Suppose a set of measurements, namely, $X_{1}, X_{2}, \ldots$, is used to measure ' $n$ ' number of experimental variables. These measurements are used to calculate some desired results (R) of the experiment. Thus,

$R=R\left(X_{1}, X_{2}, X_{3}, \ldots \ldots \ldots, X_{n}\right)$

Let $W_{R}$ be the uncertainty in the result, $R$, and $W_{1}, W_{2^{\prime}}$ $W_{3}, \ldots, W_{n}$ be the uncertainties in the independent variables. The uncertainty is calculated according to the following equation.

$W_{R}=\left[\left(\frac{\partial R}{\partial X_{1}} W_{1}\right)^{2}+\left(\frac{\partial R}{\partial X_{2}} W_{2}\right)^{2}+\ldots+\left(\frac{\partial R}{\partial X_{n}} W_{n}\right)^{2}\right]^{\frac{1}{2}}$

If the relationship between the measured parameters and the result, $R$, is known and the uncertainties in the measurement of each quantity are further known, then the error or uncertainty of the result, $\mathrm{W}_{\mathrm{R}^{\prime}}$ is calculated according to Equation (2). The measured values are very small compared with the data obtained. Table 1 shows the uncertainty values of the measured parameters. It was found that all the uncertainty values were within the allowable range.

\subsection{Properties of RDF}

The RDF fed to the solar tunnel dryer was obtained from the municipal waste treatment plant of ECARU Company located in the $15^{\text {th }}$ of May City, Egypt. Its properties are listed in Table 2.

\subsection{Solar Collector Efficiency}

Several types of solar collectors are used in engineering applications. Flat-plate solar collectors are most commonly used to heat the air inside dryers. The efficiency of a solar collector depends on many parameters such as air mass flow rate, solar radiation intensity, and inlet and outlet air temperatures of the collector. The efficiency of the flatplate solar collector can be calculated according to Sencan, A., and Ozdemir, G., (2007) as follows:

$\eta=\frac{Q_{u}}{A_{c} \times I}$

where $Q_{u}$ is the useful energy transferred to the drying air, $A_{c}$ is the collector area, $\eta$ is the solar collector thermal efficiency, and I is the intensity of solar radiation.

\subsection{Drying Efficiency Calculation}

The drying efficiency is defined as the ratio of the energy required to evaporate the moisture in the RDF sample

(a)

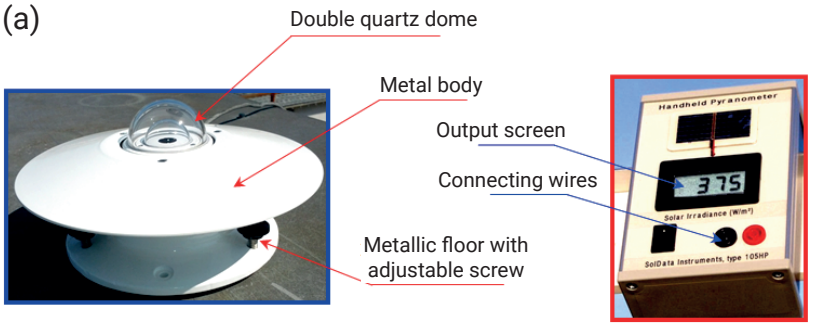

(b)
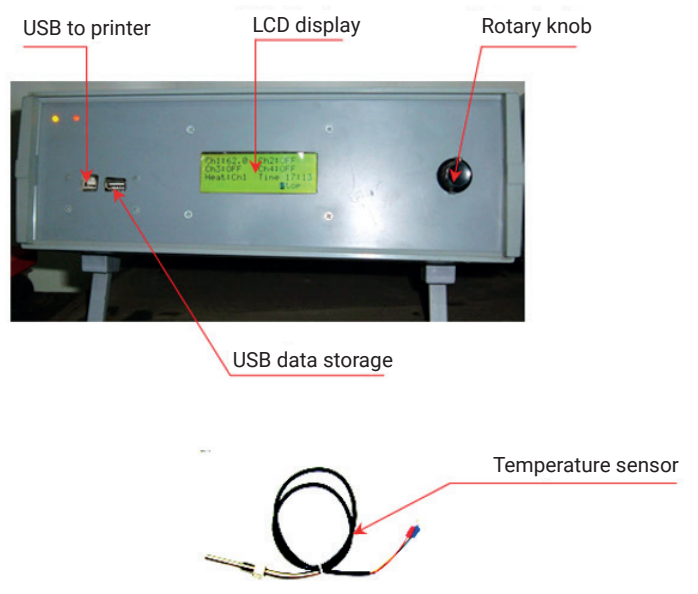

(c)

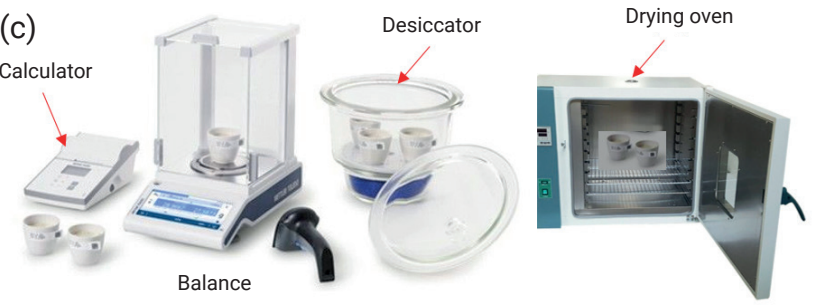

FIGURE 3: Photographs of measuring instruments. (a) Eppley PSP pyranometer with output screen. (b) Data acquisition and RTD temperature sensor. (c) Drying oven and balance apparatus. 
TABLE 1: Uncertainties in parameters measured during drying process.

\begin{tabular}{l|c} 
Measuring instrument & Uncertainty \\
\hline Mercury thermometer & 0.050 \\
\hline Eppley pyranometer & 0.002 \\
\hline RTD temperature sensor & 0.003 \\
\hline Anemometer & 0.050 \\
\hline Electronic balance & 0.001 \\
\hline
\end{tabular}

to the energy supplied to the solar tunnel dryer. It was assumed that the heat loss from the dryer to the ambient air was negligible and that heat was utilised to increase the product temperature and evaporate the moisture content of the product. The drying efficiency in a certain time period was calculated using the following expression, Kassem, A., et al. (2011):

$\eta_{t}=\frac{\left(W_{w} \times L+m_{p} \times C_{p} \times \Delta T\right)}{A \times I_{t} \times t_{h}}$

The latent heat of vaporisation is usually expressed as a function of drying air temperature. Hence, in this study, the latent heat of vaporisation $(\mathrm{J} / \mathrm{kg})$ was calculated in accordance with ASAE, (1998) as follows:

$L=2502535.259-2385.764\left(T_{d}-273.16\right), 273.16 \leq T_{d} \leq 338.72$ (5)

where $\eta_{t}$ is the drying efficiency (\%), $A$ is the surface area of the air heater $\left(\mathrm{m}^{2}\right), t_{h}$ is the desired time period, $W_{w}$ is the evaporated water $(\mathrm{kg}), \mathrm{m}_{\mathrm{p}}$ is the mass of the RDF sample at the end of this time period $(\mathrm{kg}), \mathrm{C}_{\mathrm{p}}$ is the specific heat capacity of RDF, which depends on the RDF composition and was assumed to be constant, as reported by Savage, G.,1989, $\Delta \mathrm{T}$ is the temperature difference between ambient air and air inside the solar tunnel dryer $\left({ }^{\circ} \mathrm{C}\right), \mathrm{I}_{\mathrm{t}}$ is the global solar radiation on a horizontal surface $\left(\mathrm{W} / \mathrm{m}^{2}\right)$, and $T_{d}$ is the drying air temperature inside the solar tunnel dryer $(\mathrm{K})$.

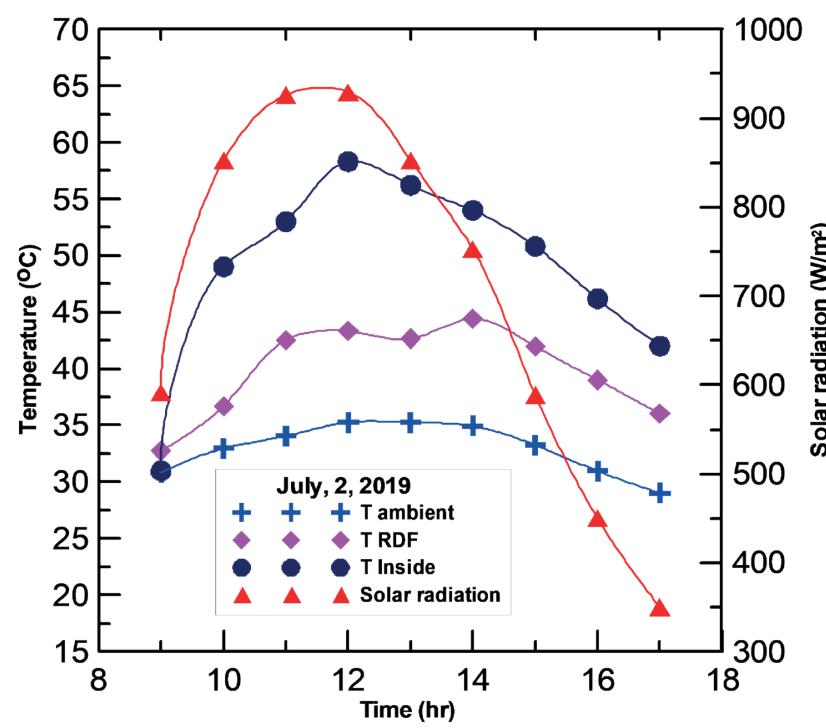

FIGURE 4: Variations in ambient, inside, and RDF temperatures and solar radiation intensity with time on 2 July 2019.
TABLE 2: Properties of RDF.

\begin{tabular}{|c|c|c|c|}
\hline No. & Parameter & Value & Unit \\
\hline 1 & Total Cl & Max. 0.7 & $\%$ \\
\hline 2 & $\mathrm{Cd}+\mathrm{Hg}+\mathrm{Tl}$ & Max. 7 & ppm SS \\
\hline 3 & As & Max. 9 & ppm SS \\
\hline 4 & $\mathrm{Cr}$ & Max. 40 & ppm SS \\
\hline 5 & Cu soluble & Max. 300 & ppm SS \\
\hline 6 & $\mathrm{Mn}$ & Max. 400 & ppm SS \\
\hline 7 & $\mathrm{Ni}$ & Max. 40 & ppm ss \\
\hline 8 & $\mathrm{~Pb}$ & Max. 200 & ppm SS \\
\hline 9 & S & Max. 0.6 & T.q. \\
\hline 10 & Size & Max. $30 \times 30$ & $\mathrm{~mm}^{2}$ \\
\hline 11 & Bulk density & $60-80$ & $\mathrm{~kg} / \mathrm{m}^{3}$ \\
\hline
\end{tabular}

SS: suspended solids; T.q.: threshold quantity.

\section{RESULTS AND DISCUSSION}

Figures 4, 5, and 6 present the variations in the ambient air, internal, and RDF temperatures as well as that of solar radiation intensity as functions of time on the days when the experiment was conducted in July 2019. The hourly solar radiation intensity started to increase from 9:00 AM (local time) and peaked at noon, thereafter decreasing until the end of the day, as shown in Figures 4-6. In addition, the maximum recorded values of solar radiation intensity were 930, 990, and $965 \mathrm{~W} / \mathrm{m}^{2}$ on 2, 4, and 6 July 2019, respectively. Furthermore, a strong relationship between the solar radiation intensity and ambient temperature was observed with their variation curves exhibiting the same trend.

The temperature inside the solar tunnel was much higher than the RDF temperature. The temperature difference started to increase in the morning, peaked at noon, and decreased thereafter until the end of the day. Increasing the air stream temperature endowed it with additional

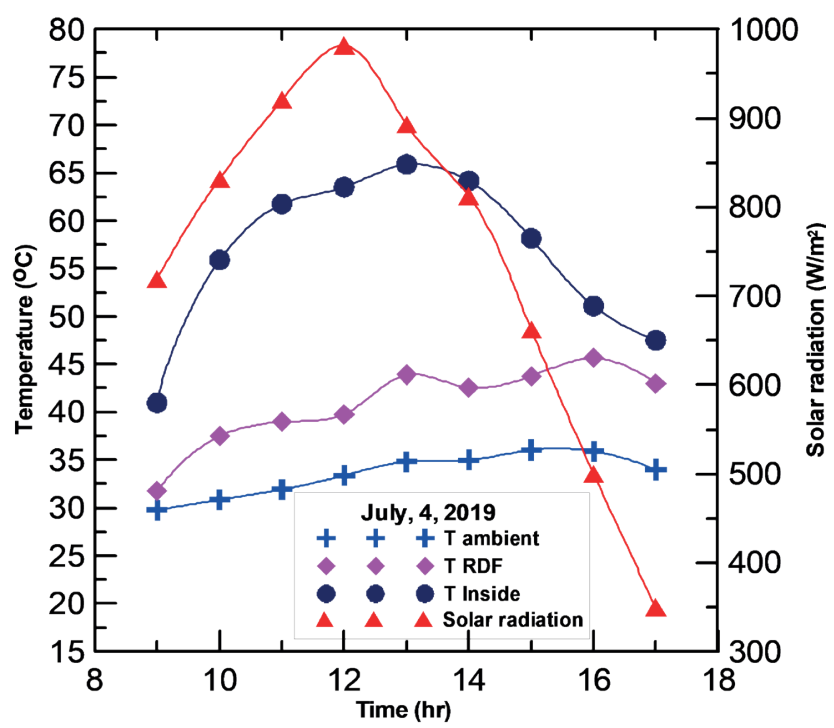

FIGURE 5: Variations in ambient, inside, and RDF temperatures and solar radiation intensity with time on 4 July 2019. 


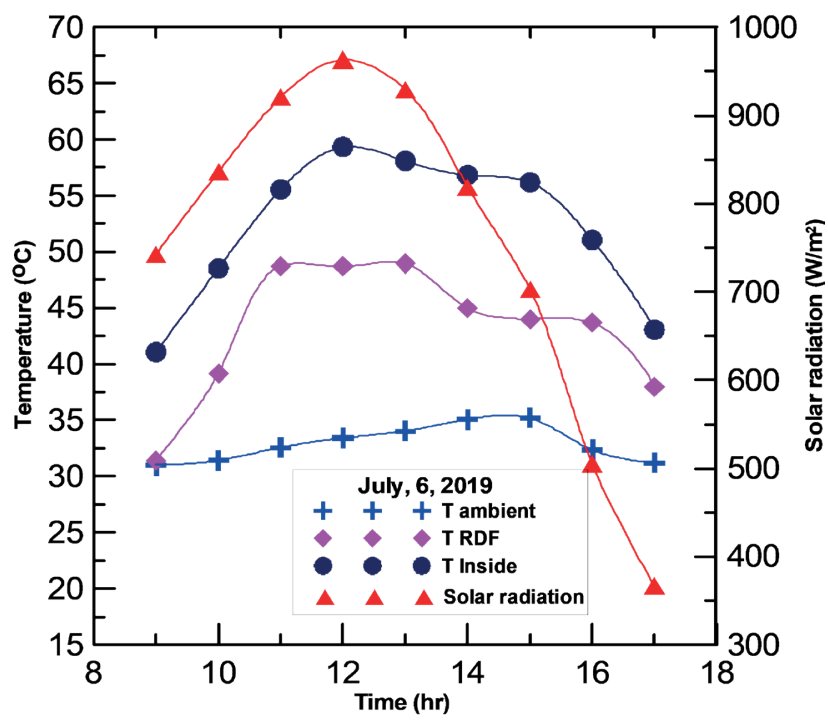

FIGURE 6: Variations in ambient, inside, and RDF temperatures and solar radiation intensity with time on 6 July 2019.

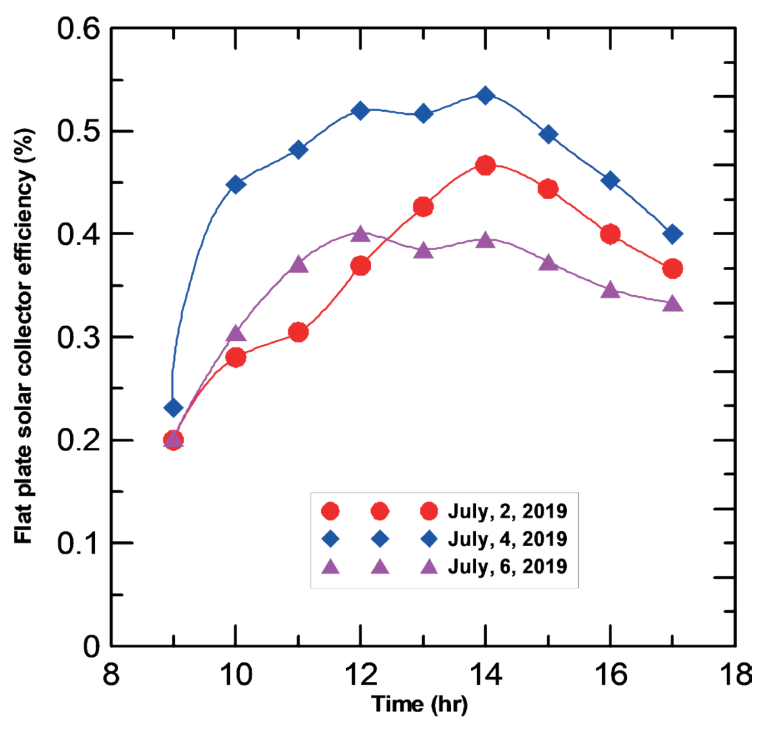

FIGURE 7: Variations in flat-plate solar collector efficiency with time on three days of when the experiment was conducted in July 2019 at air mass flow rate of $0.02 \mathrm{~kg} / \mathrm{s}$. evaporative power, which resulted in more effective drying in a shorter duration. This indicated that the drying process should be conducted at a lower airflow rate and higher drying air stream temperature. The maximum temperatures recorded inside the solar dryer were $58.3,65.8$ and $59.0^{\circ} \mathrm{C}$ on 2, 4, and 6 July 2019, respectively, and the maximum RDF temperatures on these days were 44.4, 45.6, and $48.9^{\circ} \mathrm{C}$, respectively.

It is known that wind velocity has a significant effect on the drying process, dryer efficiency, and flat-plate solar collector efficiency. The wind velocity on the days when the experiment was conducted was measured and recorded every hour using the anemometer. The average recorded values of wind velocity were $2.5,3.0$, and $3.9 \mathrm{~m} / \mathrm{s}$ on 2,4 , and 6 July 2019, respectively.

Figure 7 shows the variation in the flat-plate solar collector efficiency with local time during the days when the experiment was conducted in July 2019. The variation in the flat-plate solar collector efficiency was similar to that of the solar radiation intensity, which indicated that the proposed experimental set-up as well as its design and manufacture were error-free.

The results obtained on all three days were similar, as depicted in Figure 7. The maximum recorded values of the flat-plate solar collector efficiency were $46.6 \%, 53.4 \%$, and $40.0 \%$ on 2, 4, and 6 July 2019, respectively, at an air mass flow rate of $0.02 \mathrm{~kg} / \mathrm{s}$. To verify the accuracy of these results, they should be validated based on previously published findings. At an air mass flow rate of $0.02 \mathrm{~kg} / \mathrm{s}$, Abdullah et al. achieved maximum efficiencies of approximately $58.2 \%$ and $38.5 \%$ using a staggered double-pass and staggered single-pass solar air heaters, respectively. The maximum daily efficiency observed in their work was $68 \%$ at an air mass flow rate of $0.05 \mathrm{~kg} / \mathrm{s}$ using the staggered double-pass solar air heater. Kabeel et al. [22] used a conventional solar air heater at an air mass flow rate of $0.022 \mathrm{~kg} / \mathrm{s}$ and achieved a maximum daily efficiency of ap- proximately $32.12 \%$. Thus, the results obtained in the present work were similar to previously published findings.

The variations in the RDF moisture content with time at an air mass flow rate of $0.02 \mathrm{~kg} / \mathrm{s}$ on 2, 4, and 6 July 2019 are shown in Figure 8. The moisture content removal depends on the drying air temperature. In the present work, the increase in the air stream temperature owing to the airflow generated in the solar tunnel dryer was sufficient for the purpose of drying the RDF. Figure 8 shows that the final RDF moisture content was approximately constant at the end of the day, and this was especially the case on 4 July 2019. The moisture content of RDF decreased from $35.6 \%$ to $9.6 \%$, from $28.3 \%$ to $8.5 \%$, and from $43.5 \%$ to $14.0 \%$ on 2,4 , and 6 July 2019, respectively. The quantities of water removed on 2, 4, and 6 July 2019 were $26.0 \%, 19.8 \%$, and $29.5 \%$, respectively.

To study the power of the solar tunnel dryer, an identical quantity of RDF with the same moisture content was placed to dry in the sun for the same drying time on the days when the experiment was conducted. The results obtained using the solar tunnel dryer were compared with those of drying the samples in the sun.

Figure 9 shows the variations in the RDF moisture content versus time for the samples in the sun on the three days when the experiment was conducted in July 2019. The moisture content of the RDF samples placed in the sun decreased from $35.6 \%$ to $20.0 \%$, from $28.3 \%$ to $12.0 \%$, and from $43.5 \%$ to $29.0 \%$ on 2,4 , and 6 July 2019 , respectively. The quantities of water removed on 2, 4, and 6 July 2019 in the same drying time were $15.6 \%, 16.3 \%$, and $14.5 \%$, respectively.

The above results showed that in terms of the quantity of water removed, the RDF drying process in the solar tunnel dryer showed improvements of $40.0 \%, 17.68 \%$, and $50.85 \%$ over that in the sun on 2, 4, and 6 July 2019, respectively. Additionally, it was clear that the drying rate as well as the initial and final moisture contents of RDF played important and effective roles in the drying process and this 


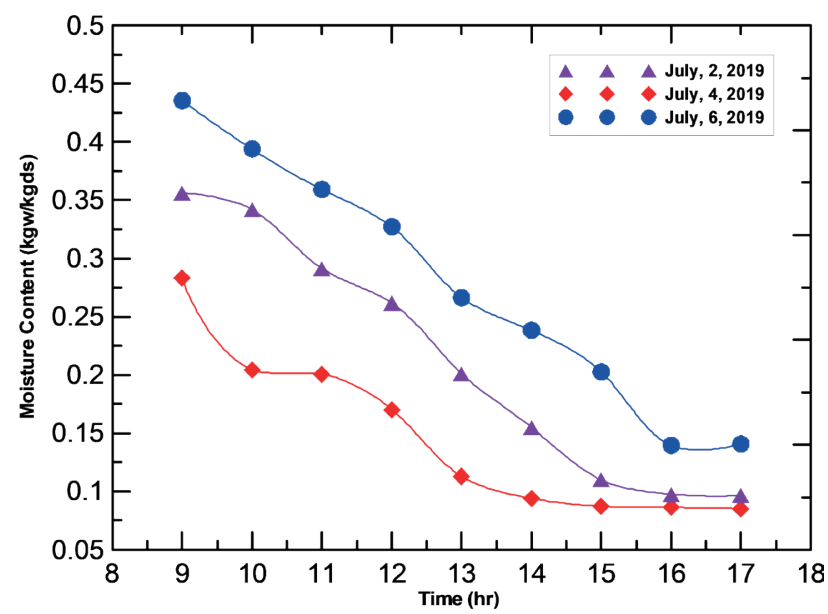

FIGURE 8: Variations in RDF moisture content with time on three days when the experiment was conducted in July 2019 at air mass flow rate of $0.02 \mathrm{~kg} / \mathrm{s}$.

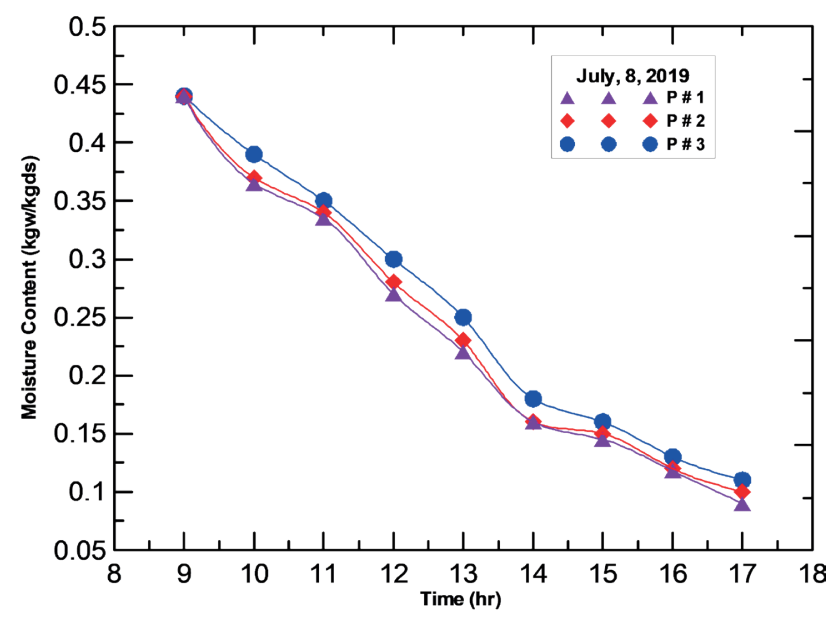

FIGURE 10: Variations in RDF moisture content with time at three different positions on 8 July 2019.

was the main reason for the different values obtained in the two processes.

To evaluate the effect of the drying air stream temperature on the drying process, the solar tunnel dryer was divided into three sections: first (P\#1), middle (P\#2), and last (P\#3). The moisture contents in the three sections were measured and recorded on 8 July 2019. The variations in the RDF moisture content with time in the three different sections are shown in Figure 10. The highest RDF drying rate was observed in P\#1, followed by those in P\#2 and P\#3. This indicated that the drying air stream temperature had an important effect on the drying process. The drying rate of RDF decreased with increase in the length of the piping system owing to the heat transfer losses throughout the system.

Furthermore, the small difference between the three sections in terms of moisture content enabled the piping system to distribute the drying air at a constant rate throughout the solar tunnel dryer.

Figure 11 shows the variations in the dryer efficiency with time on the days when the experiment was conducted

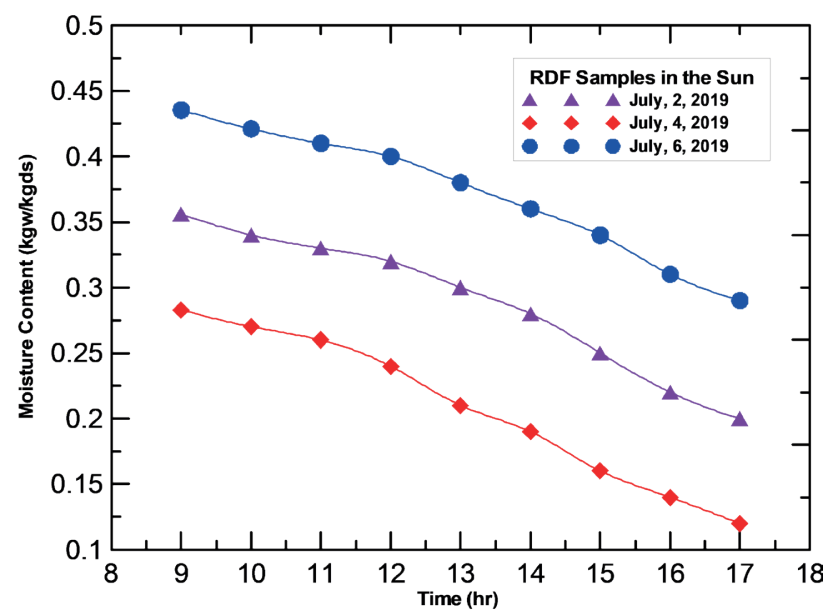

FIGURE 9: Variations in RDF moisture content with time for samples dried in the sun on three days when the experiment was conducted in July 2019.

in July 2019 at an air mass flow rate of $0.02 \mathrm{~kg} / \mathrm{s}$. The dryer efficiency and flat-plate solar collector efficiency exhibited similar variation trends and both varied with the solar radiation intensity. The increase in dryer efficiency may have been owing to the increase in the drying air temperature, which enhanced the evaporative power of air and decreased the drying time. The dryer efficiency varied in the range 14.1-29.5\% depending on the drying air stream temperature. The maximum recorded dryer efficiencies were $23.8 \%$, $29.5 \%$, and $25.8 \%$ on 2,4 , and 6 July 2019 , respectively.

\section{CONCLUSIONS}

In this study, an experimental investigation was conducted for drying RDF using a solar tunnel dryer. The dryer was manufactured using iron bars and other materials available locally. The climate conditions were measured on

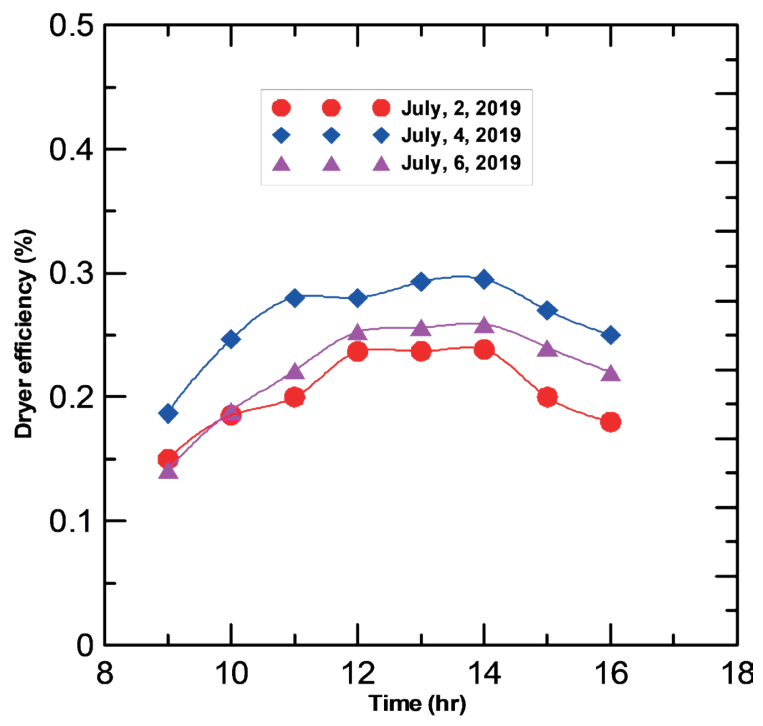

FIGURE 11: Variation in dryer efficiency with local time on three days when the experiment was conducted in July 2019 at air mass flow rate of $0.02 \mathrm{~kg} / \mathrm{s}$. 
the days when the experiment was conducted and plotted as functions of time. A flat-plate solar collector was used to heat the air stream entering the solar tunnel dryer. The results showed that the drying air stream had an important effect on the drying process and that the RDF moisture content decreased during the day. The flat-plate solar collector efficiency and dryer efficiency were evaluated and calculated according to the experimental results and validated using previously published findings. The maximum recorded values of flat-plate solar collector efficiency were $46.6 \%, 53.4 \%$, and $40.0 \%$ on 2, 4, and 6 July 2019, respectively. The moisture content of RDF decreased from $35.6 \%$ to $9.6 \%$, from $28.3 \%$ to $8.5 \%$, and from $43.5 \%$ to $14.0 \%$ on 2,4 , and 6 July 2019, respectively. Finally the dryer efficiency varied in the range $14.1-29.5 \%$ depending on the drying air stream temperature, and its maximum recorded values were $23.8 \%, 29.5 \%$, and $25.8 \%$ on 2 , 4, and 6 July 2019 , respectively.

\section{ACKNOWLEDGEMENTS}

The authors thank ECARU Company for technical guidance and financial support towards the preparation of this work in one of their fields located in the $15^{\text {th }}$ of May City for MSW treatment. We further express our gratitude to the project team of the Department of Mechanical Engineering, Suez Canal University, for cooperation during equipment installation and experimental work.

\section{REFERENCES}

Abdullah A.S., Abou Al-sood M.M., Omara Z.M., Bek M.A. and Kabeel A.E., 2018, Performance evaluation of a new counter flow double pass solar air heater with turbulators, Solar Energy, Vol. 173, pp. 398-406.

Asadi, F., Drying of Refuse-Derived Fuel (RDF), University College of Southeast Norway Faculty of Technology, Norway, 2016.

ASAE Standard, 1998. Psychrometric data. ASAE D271.2 DEC 94: 2431.

Beyene H.D., Werkneh A. A and Ambaye T.G., Current updates on waste to energy (WtE) technologies: a review, Renewable Energy Focus, 24, 2018.

Caputo A.C. and Pelagagge P.M., 2002, RDF production plants: I. Design and costs, Applied Thermal Engineering, Vol. 22, pp. 423 - 437.

Caputo A.C. and Pelagagge P.M., 2002, RDF production plants: II. Economics and profitability, Applied Thermal Engineering, Vol. 22, pp. 439-448.

Caputo A.C., Palumbo M. and Scacchia F., 2004, Perspectives of RDF use in decentralized areas: comparing power and co-generation solutions, Applied Thermal Engineering, Vol. 24, pp. 2171-2187.

Ekechukwu O. V. and Norton B., 1999, "Review of Solar-Energy Drying Systems II: An Overview of Solar Drying Technology", Energy Conversion and Management, Vol. 40, pp. 615-655.

Elicin, A.K. and Sacilik K., 2005, An experimental study for solar tunnel drying of apple. Tarim Bilimleri dergisi,Vol. 11(2), pp. 207-11.

Fadhel A, Kooli S, Farhat A and Bellghith A, 2005, "Study of The Solar Drying of Grapes By Three Different Processes", Desalination, Vol. 185, pp. 535-541.

Ferreira A.G, Gonçalves L.M and Maia C.B., 2014, Solar drying of a solid waste from steel wire industry. Applied thermal engineering, Vol. 73(1), pp. 104-110.
Golisz E., Jaros M. and Kalicka M., 2013, Analysis of Convectional Drying Processof Peach, Technical Sciences Vol.16(4), pp. 333343.

He P.J, Shao Z.H, Zhang D.Q and Shao L.M. Bio-stabilization of municipal solid waste prior to landfill: Environmental and economic assessment. III International Symposium MBT and MRF. Waste-toResources; 2009.

Holman, J. P., 1994, “Experimental Method for Engineers”, 6 ${ }^{\text {th }}$ ed. McGraw-Hill, Singapore.

Hossain, M.A., and Bala, B.K. 2007. Drying of hot chilli using solar tunnel drier. Solar Energy, Vol. 81, pp. 85-92.

Jannot Y. and Coulibaly Y., 1998, The “Evaporative Capacity” As A Performance Index For A Solar-Drier Air-Heater. Solar Energy, Vol. 63, pp. 387-391.

Kabeel A. E., 1998, Shape optimization for absorber plates of solar air collectors, Renewable Energy, Vol. 13(1), pp. 121-131.

Kabeel A.E. Performance of solar still with a concave wick evaporation surface. Energy 2009; Vol. 34(10), pp. 1504-9.

Kabeel A.E., Hamed M.H., Omara Z.M. and Kandel A.W., 2018, On the performance of a baffled glazed-bladed entrance solar air heater, Applied Thermal Engineering, Vol. 139, pp. 367-375

Kabeel A.E., Hamed M.H., Omara Z.M. and Kandeal A.W., 2017, Solar air heaters: Design configurations, improvement methods and applications - A detailed review, Renewable and Sustainable Energy Reviews, Vol. 70, pp. 1189-1206.

Kassem A.S, Al-Sulaiman M.A., Aboukarima A.M. and Kassem S.S. 2011, Predicting Drying Efficiency during Solar Drying Process of Grapes Clusters in a Box Dryer using Artificial Neural Network, Australian Journal of Basic and Applied Sciences, Vol. 5(6), pp. 230241.

Kooli, S., Fadhel A., Farhat A. and Belghith A., 2007, Drying of red pepper in open sun and greenhouse conditions: Mathematical modeling and experimental validation. Journal of Food Engineering, Vol. 79(3), pp. 1094-103.

Koser HJK, Schmalstieg G. and Siemers W., 1982, Densification of water hyacinth. Fuel, Vol. 61, pp. 791-798.

Luca A. and Raffaello C., 2015, Food waste generation and industrial uses: A review, Waste Management, Vol. 36, pp. 147-155.

Mumba J. 1996, Design and development of a solar grain dryer incorporating photovoltaic powered air circulation. Energy Conversion Management,Vol. 37(5), pp. 615-621.

Peng Lu, Qunxing Huang, A.C. (Thanos) Bourtsalas, Yong Chi, Jianhua Yan, 2017, Experimental research of basic properties and reactivity of waste derived chars. Applied Thermal Engineering, Vol. 119, pp. 639-649.

Prasad J., Vijay V.K., Tiwari G.N. and Sorayan V.P.S., 2006, Study on performance evaluation of hybrid drier for turmeric (Curcuma longa L.) drying at village scale. Journal of Food Engineering, Vol. 75, pp. 497-502.

Savage G.,1989, Thermal conductivity and specific heat of densified refuse derived fuel, Waste management \& research, vol. 7, pp. 83-92.

Sencan, A. and Ozdemir G., 2007, Comparison of thermal performance predicted and experimental of solar air collector. Journal of Applied Sciences, Vol. 7(23), pp. 3721-3728.

Usub, T., Lertsatithanakorn C., Poomsaad N., Yang L., and Siriamornpun S., 2008, Experimental performance of a solar tunnel dryer for drying silkworm pupae. Bio systems Engineering, Vol. 101, pp. 209-16

Yasuhara A., Amanoa Y. and Shibamoto T., 2010, Investigation of the self-heating and spontaneous ignition of refuse-derived fuel (RDF) during storage, Waste Management, Vol. 30, pp. 1161-1164.

Yuan J, Zhang D, Li Y, Chadwick D, Li G, Li Y and Du L.M 2017, Effects of adding bulking agents on biostabilization and drying of municipal solid waste. Waste Manage. Vol. 62, pp. 52-60.

Zamrudy W., Santosa S., Budiono A. and Naryono E., 2019, A review of Drying Technologies for Refuse Derived Fuel (RDF) and Possible Implementation for Cement Industry, International Journal of Chem Tech Research, Vol.12 (1), pp. 307-315. 